\title{
Prevalence of Intestinal Parasites Among Primary School Children in Three Geopolitical Zones of Imo State, Nigeria
}

\author{
Udensi Justina Ugochi ${ }^{1,}$, , Mgbemena Ifenyinwa C. ${ }^{1}$, Emeka-Nwabunnia Ijeoma ${ }^{1}$, \\ Ugochukwu Mmasi Godson ${ }^{2}$, Awurum Ivy Nwaku ${ }^{2}$ \\ ${ }^{1}$ Department of Biotechnology, Federal University of Technology, Owerri, Nigeria \\ ${ }^{2}$ Biology Department, Alvan Ikoku Federal University of Education, Owerri, Imo State, Nigeria
}

\section{Email address:}

udensiugochi@gmail.com (Udensi J. U.), cudeeny@gmail. com (Ugochukwu M. G.), Ivymad86@yahoo. com (Awurum I. N.), olaedo_k@yahoo.com (Emeka-Nwabunnia I.)

\section{To cite this article:}

Udensi Justina Ugochi, Mgbemena Ifenyinwa C., Emeka-Nwabunnia Ijeoma, Ugochukwu Mmasi Godson, Awurum Ivy Nwaku. Prevalence of Intestinal Parasites Among Primary School Children in Three Geopolitical Zones of Imo State, Nigeria. Science Journal of Public Health. Special Issue: Who Is Afraid of the Microbes. Vol. 3, No. 5-1, 2015, pp. 25-28. doi: 10.11648/j.sjph.s.2015030501.15

\begin{abstract}
A study of the prevalence of intestinal parasitic infection was conducted among children aged 5-16years in primary schools in rural parts of Imo State, Nigeria. Of the 337 faecal samples examined, 164 (48. 7\%) harboured intestinal parasites with $65(40.4 \%)$ being from Orlu zone, 57 (52. 7\%) from Owerri zone, and 42 (61. 8\%) from Okigwe zone. The parasites identified were Ascaris lumbricoides (41. 5\%), Hookworm (23. 8\%), Trichuris trichiura (1. 2\%), Teania spp (1. 2\%), Entamoeba histolytica (36. 6\%), and Giardia lamblia (1. 8\%). Among the helminthes, A. lumbricoides (60. 0\%) occurred highest among the age bracket of 14-16years, while E. histolytica (44. 4\%) was the highest occurring protozoan parasite among children aged 5-7 years. Generally, prevalence of infection decreased with increasing age of children, and more females (53. $9 \%$ ) than males (48. 1\%) were infected. However, there was no statistical significant difference in infection with relation to age and sex of the pupils ( $p>0.05$ ). Intestinal parasitic infection is reduced through improved personal hygiene and environmental sanitation as children with high standard of hygiene were found to be less prone to parasitic infection.
\end{abstract}

Keywords: Prevalence, Intestinal Parasites, Children, Infection, Geopolitical Zones

\section{Introduction}

Intestinal parasites are parasites that populate the gastrointestinal tract, typically protozoa and helminths are the two major types of intestinal parasites [1]. There are over 65,000 species of protozoa found in aquatic and terrestrial habitats with many adopting the symbiotic or parasitic mode of life, of which there are over 10, 000 species. Man and his domestic animals are victims of these parasitic protozoa. Intestinal parasitic infections are among the most common infections worldwide [2, 3]. Current estimates by World Health Organisation (WHO) shows that about 3. 5 billion people are infected with intestinal parasites, 450 million are ill, majority of which are children [3]. The helminthes $T$. trichiura, A. lumbricoides and the hookworms as well as the protozoa $E$. histolytica have been observed to cause infection in $800,1000,900$ and 48 million people respectively worldwide [3]. The public health importance of gastrointestinal parasites includes high morbidity in school children and in women during their child bearing years [4]. The children are mostly affected because of their vulnerability to nutritional deficiencies.

In Nigeria, a considerable amount of human and animal wastes are discharged into the soil daily leading to soil seepage with pathogenic organisms which include cysts, eggs and larvae of these intestinal parasites [5]. The distribution and prevalence of various species of intestinal parasites differ from one region to another.

\section{Aim and Objective}

This study was carried out to determine the prevalence of intestinal parasites among primary school children in parts of Imo State in order to give a baseline data on the extent and the level of infection.

\section{Materials and Methods}

The study was carried out in parts of Imo State, South Eastern Nigeria (longitude $6^{\circ} 36^{\circ} \mathrm{E}, 7^{\circ} 28^{\circ} \mathrm{E}$ and latitude 
$\left.5^{\circ} 10^{\circ} \mathrm{N}, 5^{\circ} 57^{\circ} \mathrm{N}\right)$. The major occupations of the people include farming, trading, and public service. The major sources of water supply for the inhabitats of this area are streams, boreholes, harvested rainwater, ponds and wells. Most areas also have inefficient waste disposal systems, poor drainage systems, and poor toilet facilities.

Permission was sought and obtained from the authorities in charge of the eleven primary schools used. Sixty (60) pupils were randomly selected from different classes (1-6) in each school by balloting. A total of three hundred and thirty seven (337) pupils (males and females) aged between 5 and 16 years were examined.

Data collection involved the use of questionnaires and collection of stool samples from selected pupils. Clean, dry, well labeled specimen bottles were given together with the questionnaire, one to each of the sampled children for their faecal samples a day before the collection. The collected samples were then taken to the laboratory for analysis using the direct wet mount microscopic examination and the formol-ether concentration technique as described by $[6,7,8$, 9]. The results were recorded, represented in tables and analyzed using simple percentages. Further analysis was done using Chi-square $\left(\chi^{2}\right)$ test to determine if there is any statistical significant difference betweenprevalence of parasites inthe sex and the age of the pupils.

\section{Results}

A total of 164 (48.7\%) samples were positive for different intestinal parasites out of the 337 samples examined. Six intestinal parasites were encountered throughout the study with following prevalence: Ascaris lumbricoides (41.5\%), Hookworm (23. 8\%), Trichuris trichiura (1.2\%) Taenia spp (1.2\%), Entamoeba histolytica (36.6\%), and Giardia lamblia (1.8\%) (Table 1).

The results in Table 2 show that females were more infected 110 (53. 9\%) than males 64 (48. 1\%), though statistically there was no significant difference $(\mathrm{P}>0.05)$.

In Table 3 below the highest prevalence of $83(64.8 \%)$ was observed in the age group of 11-13 yearswhile the 5-7 years age group had the least with $18(33.3 \%)$ prevalence of infection.

Among the intestinal parasites recorded, A. lumbricoides occurred highest and E. histolytica had the least prevalence. Mixed infections were encountered with the most common combination being $A$. lumbricoides and $E$. histolytica.

Table 1. Overall prevalence of gastrointestinal parasites among primary school children in Imo State.

\begin{tabular}{|c|c|c|c|c|c|c|c|c|}
\hline \multirow{2}{*}{ Schools } & \multirow{2}{*}{ No Examined } & \multirow{2}{*}{$\begin{array}{l}\text { No } \\
(\%)\end{array}$} & \multicolumn{6}{|c|}{ Number (\%) of Gastrointestinal Parasites } \\
\hline & & & Ascaris & Hookworm & Trichuris & Taenia & E. histolytica & Giardia \\
\hline ORZPS 1 & 31 & $11(35.5)$ & $3(27.3)$ & $3(27.3)$ & $1(9.1)$ & $0(0)$ & $6(54.5)$ & $0(0)$ \\
\hline ORZPS 2 & 54 & $25(46.3)$ & $11(44)$ & $3(12)$ & $0(0)$ & $1(4)$ & $11(44)$ & $2(8)$ \\
\hline ORZPS 3 & 24 & $9(37.5)$ & $4(44.4)$ & $1(11.1)$ & $0(0)$ & $0(0)$ & $4(44.4)$ & $0(0)$ \\
\hline ORZPS 4 & 29 & $8(27.6)$ & $8(100)$ & $0(0)$ & $1(12.5)$ & $0(0)$ & $0(0)$ & $0(0)$ \\
\hline ORZPS 5 & 23 & $12(52.2)$ & $7(58.3)$ & $1(8.3)$ & $0(0)$ & $0(0)$ & $5(41.7)$ & $1(8.3)$ \\
\hline OWZPS 1 & 30 & $19(63.3)$ & $10(52.6)$ & $0(0)$ & $0(0)$ & $1(5.3)$ & $8(421.7)$ & $0(0)$ \\
\hline OWZPS 3 & 30 & $15(50)$ & $5(33.3)$ & $6(40)$ & $0(0)$ & $0(0)$ & $4(26.1)$ & $0(0)$ \\
\hline OWZPS 4 & 45 & $22(48.9)$ & $6(27.3)$ & $8(36.4)$ & $0(0)$ & $0(0)$ & $8(36.4)$ & $0(0)$ \\
\hline OKZPS 1 & 31 & $20(64.5)$ & $8(40)$ & $8(40)$ & $0(0)$ & $0(0)$ & $4(20)$ & $0(0)$ \\
\hline OKZPS 2 & 37 & $22(59.5)$ & $6(27.3)$ & $9(40.9)$ & $0(0)$ & $0(0)$ & $9(40.9)$ & $0(0)$ \\
\hline TOTAL & 337 & $164(48.7)$ & $68(41.5)$ & $39(23.8)$ & $2(1.2)$ & $2(1.2)$ & $60(36.6)$ & $3(1.8)$ \\
\hline
\end{tabular}

KEY: ORZPS = Orlu Zone Primary School, OWZPS = Owerri Zone Primary School, OKZPS = Okigwe Zone Primary School.

Table 2. Intestinal parasites infection in relation to sex of primary school children in parts of Imo State.

\begin{tabular}{llll}
\hline Parasites & No positive (\%) & Male (\%) & Female (\%) \\
\hline Ascaris & $68(20.2)$ & $27(20.3)$ & $41(20.1)$ \\
Hookworm & $39(11.6)$ & $15(11.3)$ & $24(11.7)$ \\
Trichuris & $2(0.6)$ & $1(0.8)$ & $1(0.5)$ \\
Taenia & $2(0.6)$ & $0(0)$ & $2(1.0)$ \\
E. histolytica & $60(17.8)$ & $20(15.0)$ & $40(19.6)$ \\
G. lamblia & $3(0.9)$ & $1(0.8)$ & $2(1.0)$ \\
TOTAL & $174(51.6)$ & $64(48.1)$ & $110(53.9)$ \\
\hline
\end{tabular}

No. of males examined $=133$

No. of females examined $=204$

Table 3. Prevalence of the gastrointestinal parasites in relation to the age of the pupils.

\begin{tabular}{|c|c|c|c|c|c|c|c|c|}
\hline \multirow{2}{*}{ Age (Yrs) } & \multirow{2}{*}{ No. Examined } & \multirow{2}{*}{$\begin{array}{ll}\text { No. } & (\%) \\
\text { Positive } & \end{array}$} & \multicolumn{6}{|c|}{ Number (\%) of Gastrointestinal Parasites } \\
\hline & & & Ascaris & Hookworm & Trichuris & Taenia & E. histolytica & Giardia \\
\hline $5-7$ & 54 & $18(33.3)$ & $7(38.9)$ & $3(16.7)$ & $0(0)$ & $0(0)$ & $8(44.4)$ & $0(0)$ \\
\hline $8-10$ & 135 & $63(46.7)$ & $22(34.9)$ & $20(31.7)$ & $2(3.2)$ & $0(0)$ & $18(28.6)$ & $1(1.6)$ \\
\hline $11-13$ & 128 & $83(64.8)$ & $33(39.8)$ & $14(16.9)$ & $0(0)$ & $2(2.4)$ & $32(38.6)$ & $2(2.4)$ \\
\hline $14-16$ & 20 & $10(50)$ & $6(60)$ & $2(20)$ & $0(0)$ & $0(0)$ & $2(20)$ & $0(0)$ \\
\hline TOTAL & 337 & $174(51.6)$ & $68(20.2)$ & $39(22.4)$ & $2(1.1)$ & $2(1.1)$ & $60(36.6)$ & (1.7) \\
\hline
\end{tabular}




\section{Discussion}

In this study, the prevalence of $48.7 \%$ gastrointestinal parasites was observed among primary school children in parts of Imo State, this result is similar to the 50. 4\% prevalence reported in some parts of Ibadan, Oyo State, Nigeria [10]. However, in Ezinifite Community of Aguata L. G. A Anambra State, Nigeria, a lower prevalence of $30.68 \%$ was reported [11]. Some workers in Nigeria had earlier reported higher figures (82.6\%) and (86.4\%), in Ikwuano, Abia State and in Rumde, Yola, Adamawa State respectively [12]. The lower percentage rate of infection recorded in those studies could be due to a combination of factors such as: increased awareness of environmental and personal hygiene, application of de-worming programme in schools and increase in consumption of the natural remedies for intestinal parasites like garlic, black walnuts, pumpkin seeds and others

The presence of six species of intestinal parasites in this study area suggests that the prevailing environmental conditions support a wide range of parasites. Among the helminthes, the commonest was $A$. lumbricoides with the prevalence of (41. 5\%), followed by hookworm (23.8\%) and for the protozoa parasites, E. histolytica had the highest prevalence of $(36.6 \%)$. These patterns observed corroborate the findings of other researcherswho conducted survey in different parts of Nigeria [13, 14, 15, 16]. The presence of these parasites could be as a result of other factors such as poor toilet facilities (which encourages indiscriminate defaecation in bushes and farms), children playing in filthy environment as well as the geophagus habit of the children $[17,18,19]$. Inadequate supply of good water is another predisposing factor to parasitic diseases. Most inhabitants get their water from streams which are open to contamination by wastes both from human and animal faeces containing cysts, ova and/or larvae of the parasites [20,21].

The lower prevalence rates observed in the younger age group (5-7 yrs) and (8-10 yrs) as compared with the older ones (11-13 yrs) and (14-16 yrs) could indicate the pattern of behavior common to families of rural areas: the younger ones stay more in the house and as such are well taken care of by parents while the older children of the families are more exposed to households activities and other tedious errands. They are also more engaged in water based activities which include fishing, food processing (inside surface waterbodies such as sieving of fermented cassava, mashing of breadfruits, washing of bitter-leaf) and fetching of firewood from the bushes. The older age groupare used for farming activities and most of these activities are carried out barefooted thereby increasing their exposure arethese parasites. Although, these findings in prevalence rates among age group disagree with some observations of some researchers [22, 23, 24]. This could be due to the fact that their studies were more in urban settings where children of these age ranges (11-13yrs) and (14-16yrs) are conscious of their personal hygiene and hence are able to avoid as much as possible what would lead to one being infected.
From the study, it was discovered that more females (53.9\%) than males $(48.1 \%)$ were infected but statistical analysis showed that there is no significant difference $\mathrm{p}>0.05$.

\section{Conclusion}

The results from this study revealed a relatively high level of prevalence of gastrointestinal tract parasites in primary school children in some rural areas of Imo State. The pattern is probably similar in other parts of the country and beyond. Gastrointestinal parasites infection especially in children is a serious health problem causing a lot of devastating effects on children. The effects include decreased productivity, reduced rate of cognitive development, poor performance at school, increased absenteeism from school, growth retardation and higher vulnerability to other infections. There should be proper health education especially in the area of parasitic diseases, their mode of transmission, vectors, and serious emphasis on proper environmental sanitation as well as personal hygiene.

\section{References}

[1] D. R. Arora, and B. A. Brij, "Medical Parasitology," $3^{\text {rd }}$ ed., CBS Publishers and Distributors, 2012, pp. ix-x, 3-6. 233-245.

[2] Y. Gutierrez, "Diagnostic Pathology of Parasitic Infections with Clinical Correlations," $2^{\text {nd }}$ ed., Oxford University Press, 2005, pp. 354-366.

[3] WHO, "Report on Intestinal Helminths Infection in World Health Organization," Technical Report Series: 2002, vol. 789: 345-356.

[4] J. I. Mbanugo, and O. C. Abaziri, "A Comparative Study of Intestinal Infection of Pregnant and Non-Pregnant Woman in Nkpor, Anambra State, Nigeria," Nigeria Journal of Parasitology, 2002, vol. 23: 19-26.

[5] J. U. Udensi, and F. N. Opara, "Waste to Wealth: An Approach to Environmental Waste Management," International Journal of Environmental Health and Human Development, 2011, vol. 12, pp. 66-70.

[6] M. Cheesbrough, "Intestinal Nematodes: In District Laboratory Practices in Tropical Countries," Part 1 (Low Price edition). Cambridge University Press: New York, 2006, pp. $182-215$.

[7] WHO, "Training Manual on Diagnosis of Intestinal Parasites," Geneva. 2007, http: //www. who. int/wormcontrol/documents/ bench aids/training-manual/e

[8] L. Gracia, "Practical Guide to Diagnostic Parasitology," American Society for Microbiology, 2009, pp. 246-247.

[9] F. N. Opara, and B. E. B. Nwoke, "Research Technique in Biological and chemical Science: Techniques in Parasitology," Springfield Publishers Ltd, Nigeria, 2003, pp. 190-191.

[10] O. A. Adeyeba and A. M. Akinlabi, "Intestinal Parasitic Infections Among School Children in a Rural Community, South West Nigeria," Nigerian Journal of Parasitology, 2002, vol. 23, pp. 11-18. 
[11] J. I. Mbanugo, and C. J. Onyebuchi, "Prevalence of Intestinal Parasites in Ezinifite Community, Aguata L. G. A. Anambra State," Nigeria Journal of Parasitology, 2002, vol. 23, pp. 27 84.

[12] O. M. Ukpai and C. D. Ugwu, "Prevalence of Gastrointestinal Tract Parasites in Primary School Children in Ikwuano L. G. A. Abia State, Nigeria," Nigeria Journal of Parasitology, 2003, vol. 25, pp. 129-136.

[13] N. A. Agwu, "Incidence of Intestinal Helminths in School Children in Aba urban city, Abia State, Nigeria". International Journal of Environmental Health and Human Development, 2001, vol. 2, pp. 47-52.

[14] I. O. Emmy-Igbe, E. O. Ekwesianya, C. N. Ukaga, C. I. Eneanyi, and C. M. Ajaero, "Prevalence of Intestinal helminths in Students of Ihiala L. G. A of Anambra State". Parasitology, 2011, vol. 3, pp. 247-249.

[15] S. O. Sam-Wobo, C. F. Mafiana, and A. B. Idowu, "Reinfection Patterns of Ascaris Among School and Children in Ogun State, Nigeria," Nigerian Journal of Paraitology, 2004, vol. 25 , pp. $7-14$.

[16] R. M. Mordi and O. Paul, "A Study of Blood and Gastrointestinal Parasites in Edo State," African Journal of Biochemistry, 2007, vol. 6, pp. 2201-2207.

[17] J. Bethany, S. Brooker, M. Albinico, L. A. Geiger, D. Deitmert and P. J. Hotez, "Soil Transmitted Helminths Infection Ascariasis, Trichiuriasis and Hookworm," Lancet, 2006, vol. 367, pp. 21-32.
[18] G. C. Cook, C. Gordon, G. Zumba, and I. Alimuddin, "Manson's Tropical Disease," Saunder Elsevier: United Kingdom, 2009, vol. 9, pp. 9917-9965.

[19] S. Brooker, A. Clements, and D. A. P. Bundy, "Global Epidemiology, Ecology and Control of Intestinal Helminthic Infections," Advanced Parasitology, 2006, vol. 62, pp. 223265.

[20] J. A. Harp, "Parasitic Infection of the Gastro-intestinal Tract," Current Opinion in Gastroenterol. Clinic, North America, 2003, vol. 30, pp. 797-815.

[21] H. J. Marguire, "Disease Due to Helminth, Principle and Practice of Infectious Diseases," $6^{\text {th }}$ ed., Elsevier Publisher: India, 2005, pp. 258-286.

[22] P. J. Hotex, "A plan to Defect Neglected Tropical Diseases," Science Am, 2010, vol. 302, pp. 90-96.

[23] I. H. Nock, D. Dumiya, and M. Galadima, "Geo-helminthes in Soil and Stool of Pupils of Some Primary Schools in Samaru, Zaria, Nigeria," Nigeria Journal of Parasitology, 2003, vol. 24, pp. 115-122.

[24] I. E. K. Mba, and A. N. Amadi, "Helminth Infection in school children in Aba, Abia State, Nigeria," Journal of Medical Investment Practice, 2001, vol. 2, pp. 43- 45. 